\title{
Modular Synthesis of Self-Assembling Janus-Dendrimers and Facile Preparation of Drug-Loaded Dendrimersomes
}

\begin{abstract}
Sami Nummelin ${ }^{*}$,, Markus Selin $^{b}$, Sacha Legrand ${ }^{\ddagger c}$, Jarmo Ropponen ${ }^{* c}$, Jani Seitsonen ${ }^{d}$, Antti Nykänen $^{d}$, Jari Koivisto ${ }^{e}$, Jouni Hirvonen ${ }^{b}$, Mauri A. Kostiainen ${ }^{a}$, Luis M. Bimbo*b,f

Materials and methods aimed at the next generation of nanoscale carriers for drugs and other therapeutics are currently in great demand. Yet, creating these precise molecular arrangements in a feasible and straightforward manner represents a remarkable challenge. Herein we report a modular synthetic route for amphiphilic Janus-dendrimers via a copper-catalyzed click reaction (CUAAC) and a facile procedure, using simple injection, to obtain highly uniform dendrimersomes with efficient loading of the model drug compound propranolol. The resulting assemblies were analyzed by dynamic light scattering and cryogenic transmission electronic microscopy revealing the formation of unilamellar and multilamellar dendrimersomes. The formation of a bilayer structure was confirmed using cryo-TEM and confocal microscopy visualization of an encapsulated solvatochromic dye (Nile red). The dendrimersomes reported here are tunable in size, stable over time and display robust thermal stability in aqueous media. Our results expand the scope of dendrimer-based supramolecular colloidal systems and offer the means for one-step fabrication of drug-loaded dendrimersomes in the size range of $90-200 \mathrm{~nm}$, ideal for biomedical applications.
\end{abstract}

\section{Introduction}

Nanoscale drug carriers ${ }^{1}$ that facilitate drug transport through different compartments and across biological barriers ${ }^{2,3}$ have emerged as attractive structures for biomedical purposes due to their unique and distinct features e.g. high surface to volume ratio, possibility to increase circulation half-life, modulation of the pharmacokinetic profile of drugs, improved efficacy and reduced off-target toxicity. ${ }^{4-6}$ Liposomes, for instance, are dynamic supramolecular capsules self-assembled in aqueous media from natural or synthetic phospholipids, whose potential has already been capitalized by several formulations currently on the market. ${ }^{7}$ Polymersomes, on the other hand, are vesicles assembled from amphiphilic block copolymers. They are more robust than liposomes and have also found use in several applications in the biomedical field. ${ }^{8}$ Although extensively studied and displaying great potential, common to these architectures is that they can suffer from shortcomings that have so far hindered a more effective translation such as broad

\footnotetext{
a. Biohybrid Materials, Department of Bioproducts and Biosystems, Aalto University Fl-00076, Finland.

b. Division of Pharmaceutical Chemistry and Technology, Faculty of Pharmacy, University of Helsinki, FI-00014, Finland.

c. VTT-Technical Research Centre of Finland Ltd, P.O. Box 1000, FI-02044 VTT, Finland.

d. Molecular Materials, Department of Applied Physics, Aalto University, FI-00076,

Finland.

e. Department of Chemistry and Materials Science, Aalto University, Fl-00076,

Finland.

f. Strathclyde Institute of Pharmacy and Biomedical Sciences, University of Strathclyde, 161 Cathedral Street, Glasgow, G4 ORE, United Kingdom.

‡ Current address: Optitune Oy, Kaitoväylä 1, 90590 Oulu, Finland.

+ Electronic Supplementary Information (ESI) available: Instrumentation and techniques, ${ }^{1} \mathrm{H}$ NMR and ${ }^{13} \mathrm{C}$ NMR spectra, DLS data and additional cryo-TEM images. See DOI: $10.1039 / \mathrm{x} 0 \times x \times 0000 \mathrm{x}$
}

size distribution, high production costs due to complex preparation and purification methodologies, ${ }^{9,10}$ limited longterm colloidal stability, as well as some toxicity concerns in the case of polymersomes. These problems are not exclusive to liposomes or polymersomes, as designing modular synthetic nanoparticulate systems with target-specific functions represents a remarkable challenge..$^{7,11}$

Dendritic molecules are broadly approved as the fourth class of polymers in addition to linear, crosslinked, and branched polymeric structures. ${ }^{12,13}$ Dendrimers and dendrons ${ }^{14,15}$ are technologically advanced synthetic macromolecules having intrinsic structural and topological features, e.g. enhanced solubility, periodically branched primary structure and high structural uniformity. ${ }^{16,17}$ A myriad of functional groups can be precisely positioned throughout the skeleton, generating unparalleled structural versatility. ${ }^{18}$ Multivalent dendrimers and dendrons can readily serve as powerful structure-directing tectons, transfer and amplify chirality, ${ }^{19-21}$ and thus mediate the formation of hierarchically ordered assemblies and other complex systems that mimic important biological structures. ${ }^{18,22-25}$

Amphiphilic Janus-dendrimers are particularly interesting architectures. $^{26-31}$ Percec et al. discovered that such amphiphiles readily self-assemble into uniform and robust unilamellar vesicles, denoted as dendrimersomes, via simple injection from various organic solutions into water or biological buffers. ${ }^{25}$ The resulting dendrimersomes exhibit excellent mechanical properties. Moreover, their size and morphology can be modulated and even predicted with high correlation to experimental data. ${ }^{32-34}$ The repertoire has been further expanded with "single-single" Janus-dendrimers ${ }^{33-36}$ and carbohydrate-terminated amphiphilic Janus-dendrimers (glycodendrimersomes), which can form a variety of hard and 
soft bilayer vesicles ${ }^{37-41}$ and multilayer vesicles ${ }^{34,41}$ that mimic biological membranes and bind selectively to biomedically relevant lectins. Dendrimersomes have been successfully loaded with dye molecules ${ }^{25,42}$ and contrast agents for MRI applications, ${ }^{35,36,43}$ but examples with therapeutic drugs molecules are yet sparse. So far, only doxorubicin loaded via film hydration, ${ }^{25}$ plitidepsin loaded via an oil-in-water method, ${ }^{27}$ and the glucocorticoid drug prednisolone phosphate together with a MRI agent in vivo ${ }^{35}$ have been reported. The drug loading methods for all reported studies entail several experimental steps. Therefore, a fast and convenient loading of therapeutics within dendrimersomes remains elusive.

Herein we present a modular synthetic route for amphiphilic Janus-dendrimers using click-chemistry and the straightforward procedure, using simple injection, to obtain uniform dendrimersomes via simultaneous self-assembly and encapsulation of propranolol, a small molecule model drug.

\section{Results and Discussion}

\section{Design and Synthesis of Amphiphilic Janus-dendrimers}

In this work six amphiphilic Janus-dendrimers were synthesized by facile coupling of first generation hydrophobic Percec-type dendrons ${ }^{22,31}$ with two generations of hydrophilic 2,2bis(hydroxymethyl) propionic acid (bis-MPA) dendrons using click-chemistry. ${ }^{44}$ Three hydrophobic dendrons 5a-c were synthesized in four steps (Scheme 1), starting from methyl 3,4dihydroxybenzoate, methyl 3,5-dihydroxybenzoate, and methyl 3,4,5-trihydroxybenzoate 1a-c respectively. Alkylation of the benzoates with 1-bromododecane gave the first generation dendrons 2a-c with methyl ester at the apex. Corresponding alcohols 3a-c were obtained by reduction with lithium aluminium hydride in dry tetrahydrofuran (THF). Subsequent chlorination with thionyl chloride in dichloromethane $\left(\mathrm{CH}_{2} \mathrm{Cl}_{2}\right)$ followed by reaction with sodium azide in dimethylformamide (DMF) produced the target dendrons having an azide moiety at the focal point in $87 \% \mathbf{5 a}, 56 \% \mathbf{5 b}$ and $79 \% \mathbf{5 c}$ overall yield, respectively.

The first and second generation hydrophilic building blocks having propargyl moiety inserted at the apex were constructed of bis-MPA (Scheme 2). ${ }^{45,46}$ The bis-MPA dendron was selected as the hydrophilic block to replace the widely used poly(ethylene glycol), in view of a recent study which reported its excellent biocompatibility and stability. ${ }^{47}$ The $\mathrm{G} 1$ dendron 8 was synthesized in two steps from 6 by $N, N$-dicyclohexyl carbodiimide (DCC) esterification ${ }^{48}$ using 4-(dimethylamino) pyridinium $\mathrm{p}$-toluenesulfonate (DPTS) as the catalyst in dry $\mathrm{CH}_{2} \mathrm{Cl}_{2}$ followed by removal of acetal-protection with Dowex $50 \mathrm{~W}-\mathrm{X} 2$ resin in methanol ( $87 \%$ overall yield). An anhydride coupling strategy was employed for enhanced reactivity and ease of purification for the subsequent generation G2. The acetonide protected bis-MPA 6 was converted into the corresponding anhydride of isopropylidene-2,2-bis(methoxy) propionic acid through self-dehydration using DCC in dichloromethane ( $77 \%$ yield). Reaction with 8 and removal of the acetal protection gave the $\mathrm{G} 2$ dendron $\mathbf{1 0}$ in $79 \%$ overall yield over four steps. The copper(I)-catalyzed azide alkyne cycloaddition (CUAAC) reactions were performed in vials using a THF: $\mathrm{H}_{2} \mathrm{O}:$ DMSO mixture as solvent media in the presence of $\mathrm{Cu}(\mathrm{II}) \mathrm{SO}_{4}$ and sodium-L-ascorbate. After the completion of the reactions, crude products were purified by flash chromatography on $\mathrm{SiO}_{2}\left(\mathrm{CH}_{2} \mathrm{Cl}_{2} / \mathrm{MeOH}\right)$ affording the target Janus-dendrimers 11a-c and 12a-c in 92-97\% yields. The purity of the final products was higher than $99 \%$, as demonstrated by a combination of thin layer chromatography (TLC), ${ }^{1} \mathrm{H}-\mathrm{NMR},{ }^{13} \mathrm{C}-$ NMR, size exclusion chromatography (SEC), mass spectrometry (ESI-TOF-MS), and elemental analysis (Supporting information). The final products were extracted with $1 \mathrm{M}$ ethylenediaminetetraacetic acid (EDTA) solution to remove any traces of copper. The copper residues were found to be below $35 \mathrm{ppm}$, as detected by flame Atomic Absorption Spectrometry (AAS) after EDTA treatment, which are reportedly acceptable levels for future biological applications. ${ }^{49}$ All amphiphilic Janusdendrimers and their short notations are illustrated in Fig. 1.

\section{Self-Assembly of Janus-Dendrimers in Aqueous Solution Dynamic Light Scattering (DLS) analysis}

All Janus-dendrimers were readily soluble in ethanol, THF and acetone. The injection of Janus-dendrimers from an organic solution into water is an easy and straightforward method to fabricate dendrimersomes, in contrast to the film hydration technique which entails a more extensive experimental procedure. The Z-average size, polydispersity index (PDI), and stability over time and temperature of the resulting assemblies were investigated by DLS experiments.

Scheme 1. Synthesis of hydrophobic $\mathrm{AB}_{2}$ - and $\mathrm{AB}_{3}$-branched Percec-type dendrons ${ }^{a}$

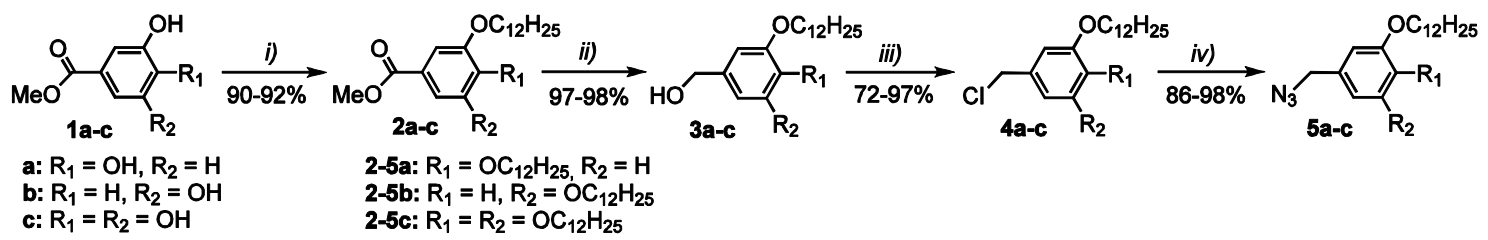

${ }^{a}$ Reagents and conditions: i) $\mathrm{C}_{12} \mathrm{H}_{25} \mathrm{Br}, \mathrm{K}_{2} \mathrm{CO}_{3}, \mathrm{DMF}, 70{ }^{\circ} \mathrm{C}, 8 \mathrm{~h}$; ii) $\mathrm{LiAlH}_{4}, \mathrm{THF}, 0$ to $25^{\circ} \mathrm{C}, 6 \mathrm{~h}$; iii) $\mathrm{SOCl}_{2}, \mathrm{cat}_{\mathrm{DMF}} \mathrm{CH}_{2} \mathrm{Cl}_{2}, 2 \mathrm{~h}$; iv) $\mathrm{NaN}, \mathrm{DMF}, 80{ }^{\circ} \mathrm{C}, 6 \mathrm{~h}$. 
Scheme 2. Synthesis of hydrophilic propargyl-modified bis-MPA dendrons ${ }^{b}$

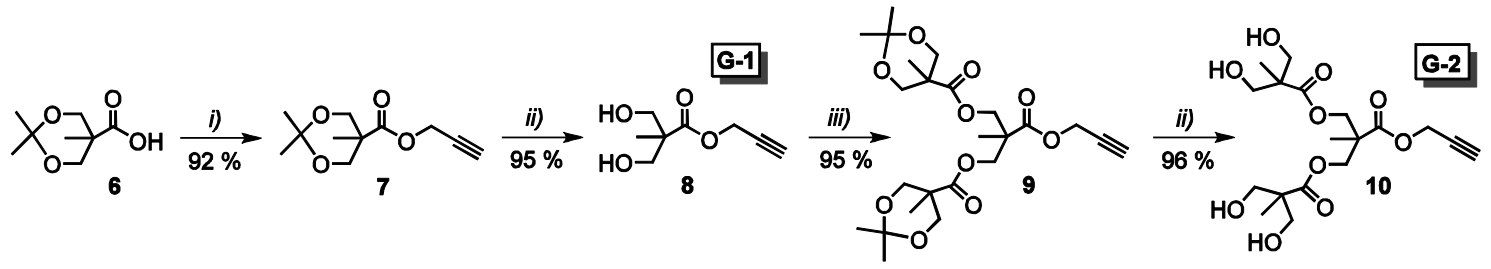

${ }^{b}$ Reagents and conditions: i) propargyl alcohol, DPTS, DCC, $\mathrm{CH}_{2} \mathrm{Cl}_{2} \mathrm{rt}, 16 \mathrm{~h}$; ii) DOWEX H+ , $\mathrm{MeOH}, 40{ }^{\circ} \mathrm{C}, 5 \mathrm{~h}$; iii) anhydride of isopropylidene-2,2-bis(methoxy) propionic, DMAP, pyridine, $\mathrm{CH}_{2} \mathrm{Cl}_{2}, \mathrm{rt}, 12 \mathrm{~h}$.

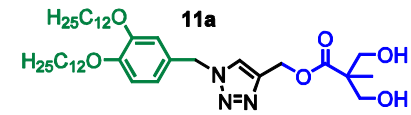

3,4-G1

DLS: $242 \mathrm{~nm}(0.23)$ dendrimersomes

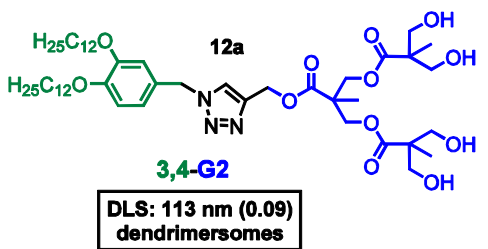

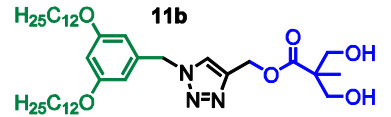

3,5-G1

DLS: 103 nm (0.06) dendrimersomes

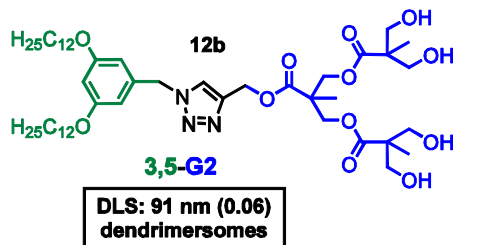

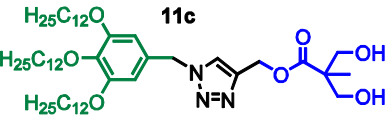

3,4,5-G1

DLS: $79 \mathrm{~nm}(0.14)$ multilamellar dendrimersomes

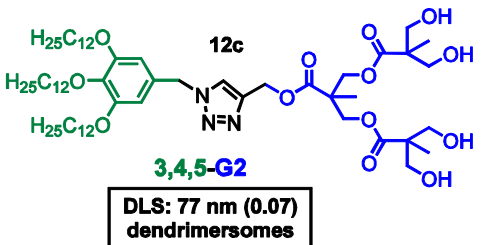

Fig. 1. Amphiphilic Janus-dendrimers, their short notations and summary of the assemblies in Milli- ${ }^{\circledR}$. The diameter (Z-avg. size in $n m$ ) and polydispersity index (in parenthesis) were measured by DLS $\left(c=0.5 \mathrm{mg} \mathrm{mL}^{-1}\right)$. Indicated morphologies were determined by cryo-TEM.

In general, fast injection from a dilute ethanol solution $(10 \mathrm{mg}$ $\mathrm{mL}^{-1}$ ) into Milli- ${ }^{\circledR}$ (final concentrations $0.1-4.0 \mathrm{mg} \mathrm{mL}{ }^{-1}$ ) produced highly uniform dendrimersomes with Z-average sizes ranging from $58 \mathrm{~nm}$ to $315 \mathrm{~nm}$ and PDI from 0.06 to 0.23 (Figs. S8-S13, Supporting Information). No additional purification was applied. The PDI values were remarkably low and below the threshold value 0.2 that is considered monodisperse for vesicles ( $\mathrm{PDI}=0$ corresponds to a uniform size distribution). ${ }^{25}$ Injection from a dilute THF and acetone solutions $\left(5 \mathrm{mg} \mathrm{mL}^{-1}\right)$ into Milli$\mathrm{Q}^{\circledast}\left(c=0.1-1.0 \mathrm{mg} \mathrm{mL}^{-1}\right)$ produced assemblies in the size range of 118-350 nm (PDI 0.04-0.12) (Figs. S14-S19, Supporting Information) and 56-249 nm (PDI 0.02-0.32) (Figs. S20-S25, Supporting Information), respectively. The 3,4-G1 (11a) dendrimers precipitated immediately when injected from ethanol (10 mg mL-1) into Milli-Q ${ }^{\circledR}$ at various concentrations. However, assemblies were formed when 11a was injected from a more diluted ethanolic stock solution $\left(5 \mathrm{mg} \mathrm{mL}^{-1}\right)$. The formation of assemblies in solution is a fast self-assembling process. ${ }^{32}$ We postulate that the slow dynamics of assembly of 3,4-G1 (11a) results in aggregation before ordered structures can be formed in solution, probably due to the combination of unfavourable conformation and high local concentration of 11a in solution. Janus-dendrimers injected from an ethanol solution exhibited monomodal size distribution in the reported concentration range. The only exceptions were 3,4-G2 (12a, $c=$ $4.0 \mathrm{mg} \mathrm{mL}^{-1}$ ), which formed gel during the DLS measurement, and 3,4,5-G2 (12c, $\left.c=2.0 \mathrm{mg} \mathrm{mL}^{-1}\right)$ which showed broad size distribution (PDI 0.37). All samples had negative electrokinetic potential in Milli- ${ }^{\circledR}$, having measured $\zeta$-potentials ranging from -18.7 to $-9.8 \mathrm{mV}$ (Table S1, Supporting Information). As a general trend, we observed a clear dependence of size of dendrimersomes vs. final concentration of dendrimers which can be further seen in Fig. S26 (Supporting Information), where we injected the dendrimers from ethanolic stock solutions with different dendrimer concentrations into Milli- $Q^{\circledR}$. When injected from ethanol, THF or acetone into Milli- ${ }^{\circledR}$, the Zaverage size increased with concentration, while PDI remained extremely low (mostly below 0.10 ). Furthermore, assembly size was dependent on branching sequence and the solvent media from which they were injected (Figures S8-S26, Supporting Information). This discovery of size modulation is an important asset for future applications, since the accumulation of liposomes 2,50 and the drug release profile from liposomes in vivo has been shown to be size-dependent. ${ }^{51} \mathrm{~A}$ size range of 90-200 $\mathrm{nm}$ is thought to be desirable for most intravenous drug delivery applications, ${ }^{52}$ with the dendrimersomes produced in this study falling within that range. It should be mentioned, however, that for some applications the dendrimersome concentrations studied here are low, i.e. if dendrimersomes are to be loaded with low potency compounds at these concentrations, the system might not achieve clinical efficacy once administered.

Next, we investigated the stability and the size distribution of assemblies as a function of temperature and time. All samples were prepared via injection from ethanol $\left(c=0.5 \mathrm{mg} \mathrm{mL}^{-1}\right)$ and annealed from $25^{\circ} \mathrm{C}$ to $70^{\circ} \mathrm{C}$. We excluded 3,4-G1 (11a) and 3,4G2 (12a), which were unstable after injection and over time. The results show excellent thermal stability with no considerable budding or merging observed (Fig. 2a). Notably, G2 dendrimer- 
based structures 3,5-G2 (12b) and 3,4,5-G2 (12c) (Fig. 2a in red) retained their size and PDI during the annealing, having a Zaverage size and PDI (in parenthesis) of $86 \pm 3 \mathrm{~nm}(0.06 \pm 0.02)$ for $3,5-\mathrm{G} 2$ and $77 \pm 2 \mathrm{~nm}(0.04 \pm 0.01)$ for $3,4,5-\mathrm{G} 2$ throughout the whole temperature range. The robust thermal stability is remarkable and comparable to polymersomes having much thicker bilayer wall. ${ }^{53}$ The stability of the assemblies over time obtained via ethanol injection ( $\left.c=0.5 \mathrm{mg} \mathrm{mL}^{-1}\right)$ was also monitored at $25^{\circ} \mathrm{C}$ (Fig. 2b). The structures self-assembled from Janus-dendrimers having 3,5- or 3,4,5-branching sequence were stable and uniform in size up to 130 days (d) and beyond, whereas 3,4-G1 (11a) assemblies were stable only $22 \mathrm{~d}$ and 3,4G2 (12a) 11 d (data not shown).

a

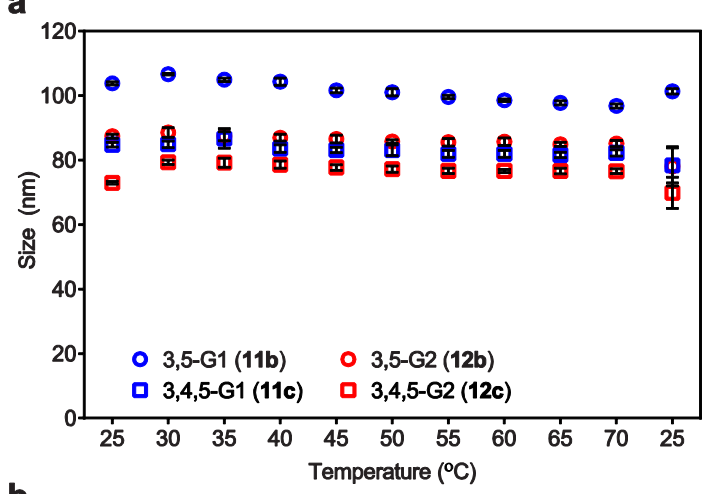

b

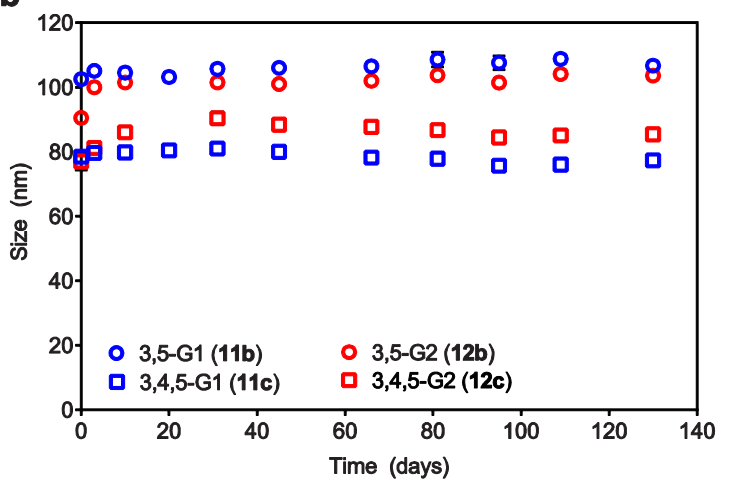

Fig. 2 a) Stability of the assemblies as a function of temperature; b) Stability of assembly size over time at ambient temperature. Janus-dendrimers were injected from ethanol ( $c$ $=0.5 \mathrm{mg} \mathrm{mL}^{-1}$ ) in Milli- $\mathrm{Q}^{\oplus}$ and measured in triplicate at each temperature and time point. Error bars represent $\pm S D$.

Likewise, we monitored the stability over time of all six structures injected from THF and acetone in ambient temperature. Janus dendrimers injected from THF into Milli- $Q^{\circledR}$ produced higher Z-average size when compared to the injections from ethanol or acetone. The 3,4-G1 (11a) were stable for $11 \mathrm{~d}$ when injected from THF (Fig. S27), and only for 5 $d$ when injected from acetone (Fig. S28). However, the 3,4-G2 (12a) assembly lasted $22 \mathrm{~d}$ (injected from THF) before visible particles emerged (Fig. S27). The 3,4-G2 (12a) injected from acetone formed the most stable assembly of all 3,4-branched Janus-dendrimers lasting nearly $90 \mathrm{~d}$ (Fig. S28). However, after ca. $50 \mathrm{~d}$, the particle size almost doubled from the initial $115 \mathrm{~nm}$ to $226 \mathrm{~nm}$, suggesting merging and aggregation before precipitation. The poor stability of $3,4-G 1$ and $3,4-G 2$ is in agreement with related 3,4-branched structures reported by Filippi et al. ${ }^{35,36}$ We assume that this is likely due to the different packing motif of the constituting alkyl tails of the 3,4-branching sequence, which are less imbricated or interdigitated than the 3,5- or 3,4,5-branched structures. ${ }^{32}$ Therefore, the dynamic processes within the bilayer involving amphiphile exchange via diffusion require less energy and can result in lower stability of these assemblies. ${ }^{54}$ Moreover, we investigated the stability of the dendrimersomes in a biologically relevant setting. Only stable (in Milli- $Q^{\circledR}$ ) Janus-dendrimers $11 \mathbf{b}, \mathbf{c}$ and $\mathbf{1 2 b}, \mathbf{c}$ were injected into Milli- ${ }^{\circledR}\left(c=3 \mathrm{mg} \mathrm{mL}^{-1}\right)$ followed by dilution in Foetal Bovine Serum (FBS) in a 1:9 ratio. Samples were incubated at $37{ }^{\circ} \mathrm{C}$ and the Z-average size (Fig. 3a) and PDI (Fig. $3 b)$ were measured each day for seven days. As it happens with liposomes, the size of the dendrimersomes increases when in contact with serum proteins, as the proteins surround the nanostructures leading to the formation of a rich protein shell termed "protein corona". ${ }^{55}$ This "corona" influences the interactions between nanoparticles and living cells, effectively determining what is "seen" by the living organism. ${ }^{56}$ The Zaverage sizes of 3,5-G1 $(260 \pm 20 \mathrm{~nm}), 3,4,5-\mathrm{G} 1(180 \pm 10 \mathrm{~nm}), 3,5-$ $\mathrm{G} 2(275 \pm 30 \mathrm{~nm})$ and $3,4,5-\mathrm{G} 2(220 \pm 40 \mathrm{~nm})$ were measured over the course of seven days (Fig. 3a). PDI variation between $-20 \%$ and $+20 \%$ of the value at day one for the first generation and $70 \%$ and $+70 \%$ for the second generation was also observed (Fig. 3b). Dendrimersomes based on similar architecture displayed comparable behaviour and were deemed suitable for intravenous administration. ${ }^{35,36}$
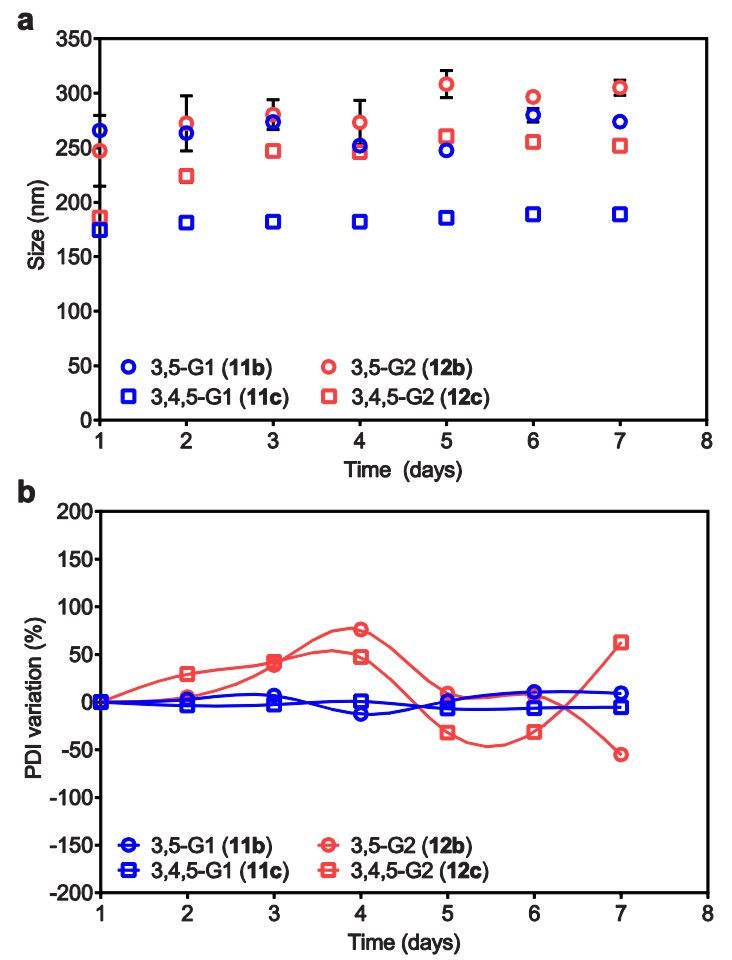

Fig. 3 a) Stability of the assemblies as a function of time in FBS. b) Change (\%) in polydispersity index (PDI) over time (7d). Janus-dendrimers were injected from ethanol into Milli- $Q^{\otimes}\left(c=3 \mathrm{mg} \mathrm{mL}^{-1}\right)$ and then diluted in FBS for a final concentration of $90 \% \mathrm{FBS}$. All samples were measured in triplicate at each time point. Error bars represent \pm SD. 
3,4

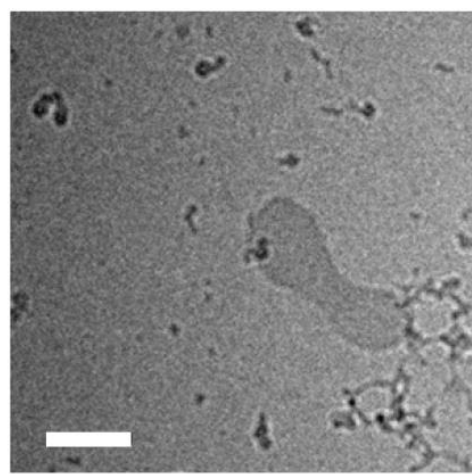

G1

G2

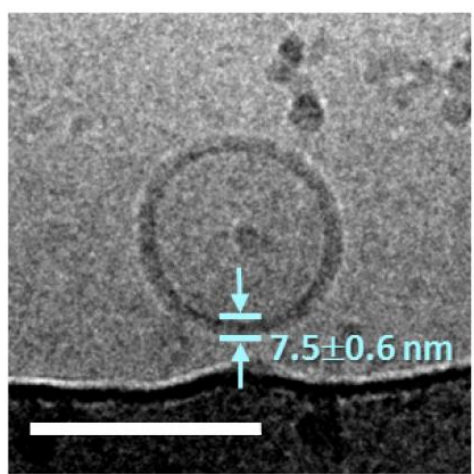

3,5
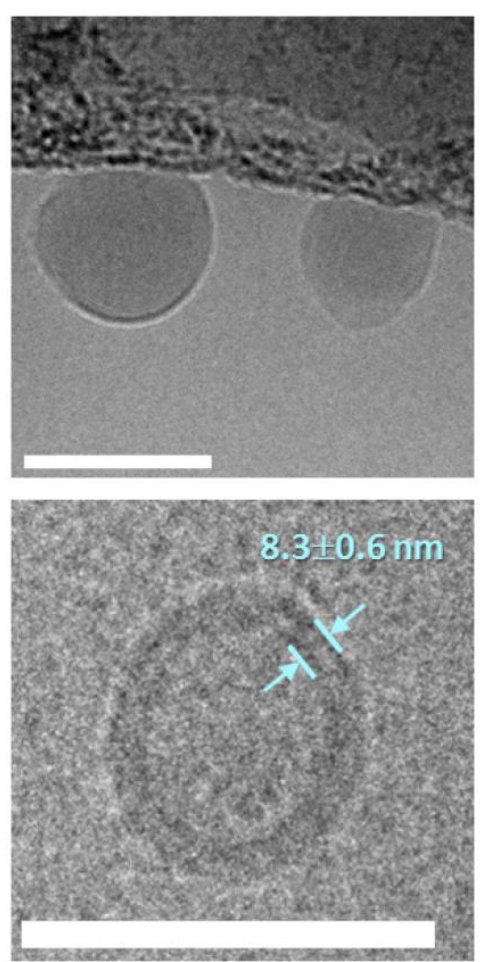

$3,4,5$
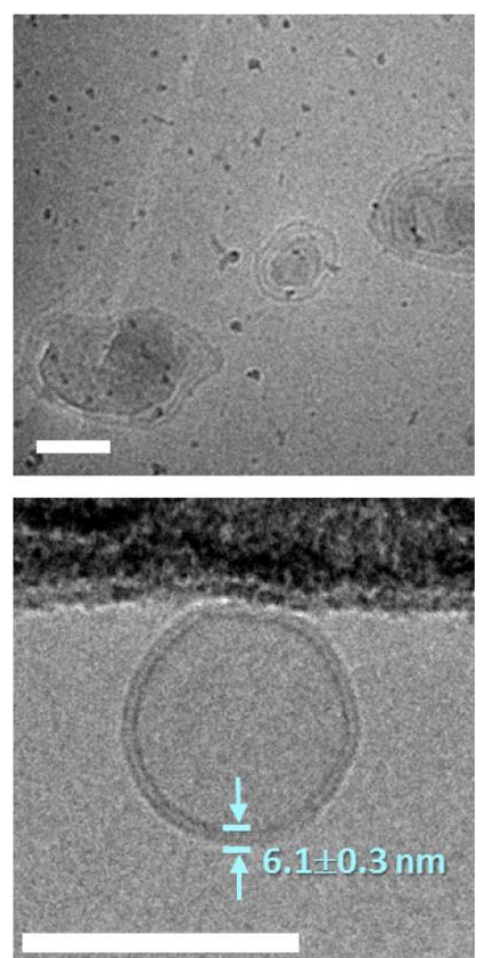

Fig. 4 Representative cryo-TEM images illustrating dendrimersomes self-assembled via injection of their ethanolic solutions into Milli- $Q^{\circledast}\left(c=0.5 \mathrm{mg} \mathrm{mL}^{-1}\right.$, respectively, except for $3,5-\mathrm{G} 2$ where $\left.c=0.125 \mathrm{mg} \mathrm{mL}^{-1}\right)$. Values of bilayer thicknesses for G2-dendrimersomes are an average of ten measurements. Scale bars are $100 \mathrm{~nm}$.

\section{Elucidation of the assemblies using microscopic methods}

Structures in aqueous solution were investigated by cryogenic transmission electron microscopy (cryo-TEM). Samples were freshly prepared via injection from an ethanol solution $(100 \mu \mathrm{L}$ of $5 \mathrm{mg} \mathrm{mL}^{-1}$ ) into $900 \mu \mathrm{L}$ of Milli- $\mathrm{Q}^{\circledR}$, with a final concentration of $0.5 \mathrm{mg} \mathrm{mL}^{-1}$, except 3,5-G2 ( $\left.c=0.125 \mathrm{mg} \mathrm{mL}^{-1}\right)$. Cryo-TEM images with measured bilayer thicknesses for G2dendrimersomes are shown in Fig. 4. We could discern both unilamellar dendrimersomes (11a,b and 12a-c) and multilamellar dendrimersomes (11c) which resemble the onionlike structures reported by Percec group. ${ }^{34,41}$ Additional images illustrating the dendrimersomes' uniform size distribution are shown in Fig. S29 (Supporting Information). However, the cryoTEM images also showed that 3,5-G2 (12b) structures, besides having a uniform population ( $\mathrm{S} 30 \mathrm{a}$ ), also displayed a number of hollow-core multilayer dendrimersomes (S30b). These structures are substantially different from the 3,4,5-G1 structures depicted in Fig. 4 and as samples at lower concentrations were imaged, this phenomenon drastically diminished. We hypothesize that this is most likely due to the cryo-TEM sample preparation method, where the structures were disrupted during the blotting procedure and when the bilayer is re-formed in a more concentrated volume, these new structures were generated.

The higher generation structures having eight (G3) or sixteen (G4) hydroxyl groups at the periphery did not self-assemble into dendrimersomes (not shown). Instead, all three G3 structures self-assembled into fibres giving rise to mechanically robust supramolecular hydrogels in Milli- ${ }^{\circledR}$, even at very low mass proportion ( $0.2 \%$ by mass). ${ }^{57}$

The formation of a bilayer structure was further corroborated by the localization of a solvatochromic dye Nile Red (NR) within the dendrimersome wall of giant dendrimersomes (Fig. 5a). Giant unilamellar dendrimersomes ( $c a .10 \mu \mathrm{m}$ in size) with uniform spherical morphology (Fig. 5b) were obtained by film hydration, ${ }^{25}$ as seen by confocal microscopy imaging. The hollow cavity of these vesicles can also be visualized from the reconstitution of the collected z-stacks (Fig. 5c).

\section{Loading of dendrimersomes with a model drug}

Film hydration as a drug-loading method entails an extensive handling protocol, offers little control over assembly size and often produces structures with broad size distribution. Therefore, we postulated that a direct injection method could be a convenient and straightforward method for loading dendrimersomes with a payload of interest. In order to discern between free and encapsulated payload, the solvatochromic dye NR was loaded in dendrimersomes self-assembled from 3,4,5-G1 (11c) or 3,5-G2 (12b). The NR acts as a hydrophobic probe, where its fluorescence maxima varies depending on the relative hydrophobicity of the surrounding environment, whereas in aqueous media NR fluorescence is completely quenched. 58 


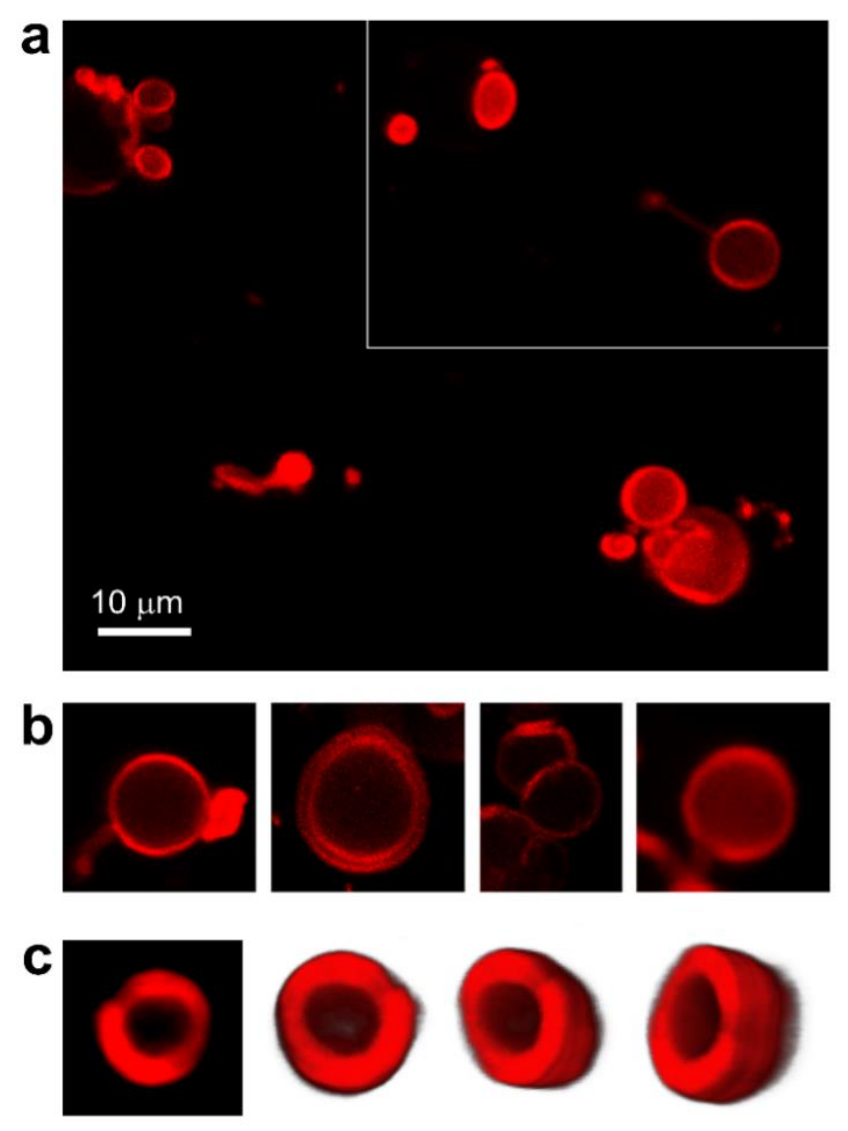

Fig. 5 a) Confocal microscopy of Nile Red-encapsulated giant dendrimersomes assembled from 3,5-G2 (12b) obtained by film hydration (scale bar is $10 \mu \mathrm{m}$ ); b) individual giant dendrimersomes with NR inside the vesicles' bilayer; c) 3D reconstruction of a dendrimersome from confocal z-stacks.

The solutions of $\mathbf{1 1 c}$ or $\mathbf{1 2 b}$, together with the NR mixture were injected into Milli- $Q^{\circledR}$ (final $c=490 \mu \mathrm{g} \mathrm{mL}^{-1}$ of $11 \mathrm{c}$ or $12 \mathrm{~b}$ and $3.14 \mu \mathrm{M} N R$ in $5 \%(\mathrm{v} / \mathrm{v})$ ethanol). As a control, NR was injected into Milli-Q ${ }^{\circledR}$ (neat or in $98 \mu \mathrm{L}$ of pure ethanol) at the same ratios as with the dendrimersomes. We noticed that only the $11 \mathrm{c}$ and 12b NR-dendrimer mixtures injected into in Milli- $Q^{\circledR}$ had a red colour under visible light (Figs. 6a and S31 Supporting Information, respectively) and strong absorption under UV light (data not shown). The Z-average size of the NR-loaded dendrimersomes 3,4,5-G1 (11c: $72.8 \pm 0.5 \mathrm{~nm}, \mathrm{PDI} 0.11$ ) and 3,5G2 (12b: $87.6 \pm 1.1 \mathrm{~nm}$, PDI 0.03) dropped to $14.4 \pm 0.5 \mathrm{~nm}$ and $9.8 \pm 0.1 \mathrm{~nm}$ after addition of $500 \mu \mathrm{L}$ of $3 \%$ Triton $\mathrm{X}-100$ per $1 \mathrm{~mL}$ of the solutions, thus confirming the disruption of the dendrimersomes. In comparison, the Z-avg. size of neat dendrimersome controls (11c: $76.0 \pm 0.9 \mathrm{~nm}$, PDI 0.14; 12b: $86.41 \pm 0.9 \mathrm{~nm}, \mathrm{PDI} 0.05)$ dropped to $9.4 \pm 0.1 \mathrm{~nm}$ and $10.1 \pm 0.2$, respectively. The fluorescence scan revealed that the NRloaded dendrimersomes had fluorescence maxima at $635 \mathrm{~nm}$ (Fig. 6b), unlike the controls, which showed no fluorescence throughout the entire measured wavelength range. The fluorescence spectra combined with the DLS and UV-irradiation results confirm the successful loading of NR into the dendrimersome bilayer.
Next, we tested the feasibility of the injection method with the self-quenching drug propranolol free base. Propranolol (PR) is a basic compound with a pKa value $9.68^{59}$ that has been shown to associate with liposomal membranes at $\mathrm{pH} 7.4 .60$ Selfquenching of propranolol fluorescence occurs at concentrations above $1 \mathrm{mM}$ in aqueous solutions and increases as a function of the drug concentration. To obtain a fluorescent signal and to avoid self-quenching in the non-encapsulated proportion of propranolol, an overall concentration of $25 \mu \mathrm{M}$ propranolol was used in the samples and in the fluorescence control. At this concentration, the calculated fluorescent lifetime of propranolol (16 ns) is above the empirical lifetimes reported in literature. ${ }^{61}$ The loading of PR within the bilayers of dendrimersomes was expected to increase the local concentrations of the drug and lead to self-quenching in the encapsulated proportion, and thereby the self-quenching was also expected to reduce the overall measurable fluorescence intensity.

Solutions of 3,4,5-G1 (11c) and 3,5-G2 (12b) were mixed with $\mathrm{PR}$ solution and the mixtures were separately injected into Milli$\mathrm{Q}^{\circledR}$, and $\mathrm{PR}$ in $10 \%$ ethanol was used as the fluorescent control. This enabled the comparison of the fluorescence of free $P R$ in the control and the overall fluorescence of $P R$ in the dendrimersome containing samples (final $\mathrm{c}=490 \mu \mathrm{g} \mathrm{mL}$ dendrimer in $10 \%(\mathrm{v} / \mathrm{v})$ ethanol) at the same overall drug concentrations (Fig. 6c). The propranolol fluorescence was quenched in the presence of 3,4,5-G1 (11c) and 3,5-G2 (12b) dendrimersomes, and the quenching was stable through time. The relative fluorescence of the PR-loaded $\mathbf{1 1}$ c dendrimersomes was slightly lower ( $c a .15 \%$ ) than that of $\mathbf{1 2} \mathbf{b}$ dendrimersomes. Two things should be considered when interpreting this result. Firstly, the fraction of the total PR loaded into 3,4,5-G1 (11c) may be larger than the fraction of the total PR loaded into 3,5G2 (12b). As PR is mainly expected to be encapsulated in the bilayers constituting the dendrimersomes, the molar dendrimer-to-drug ratios (22.8 and 21.6 for the $\mathbf{1 1 c}$ and $\mathbf{1 2 b}$, respectively) have some potential to cause higher PR-loading in the $\mathbf{1 1 c}$ than $\mathbf{1 2 b}$ dendrimersomes. Secondly, loading of similar fractions of the total PR may lead to higher local concentrations of $P R$ in multilamellar 3,4,5-G1 (11c) than in 3,5-G2 (12b) dendrimersomes. Based on the size of the loaded dendrimersomes and the morphologies seen in cryo-TEM, we speculate that the multilamellar dendrimersomes 11c incorporate higher number of Janus-dendrimers per dendrimersome and, thus, are less numerous in solution at the same concentration than unilamellar 3,5-G2 (12b) dendrimersomes. 


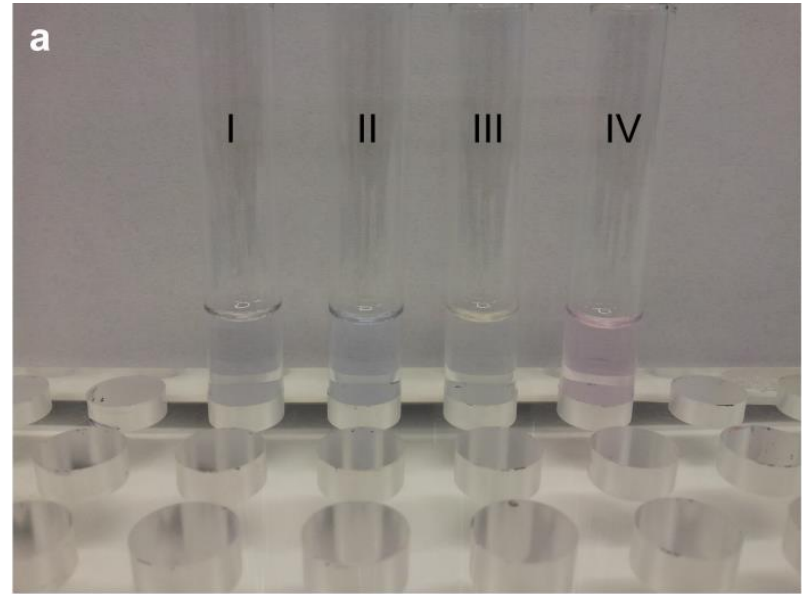

b

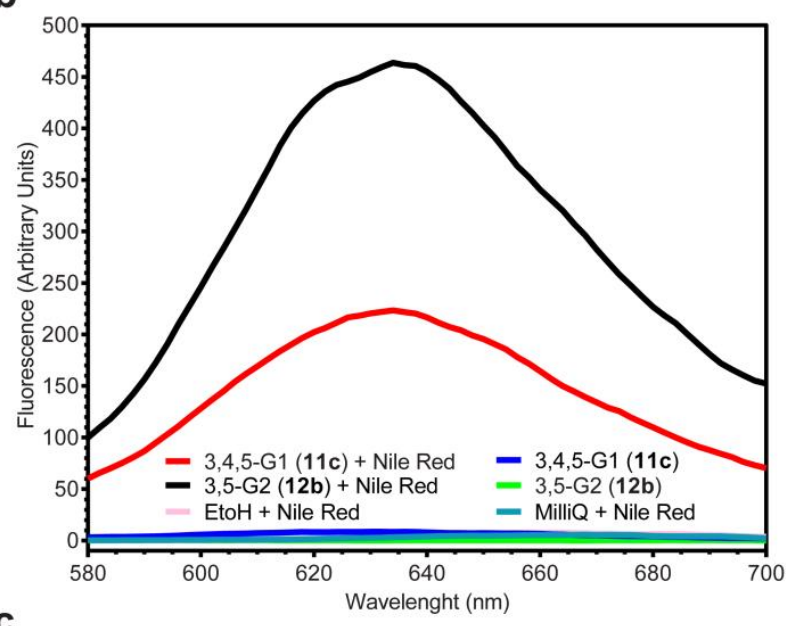

C

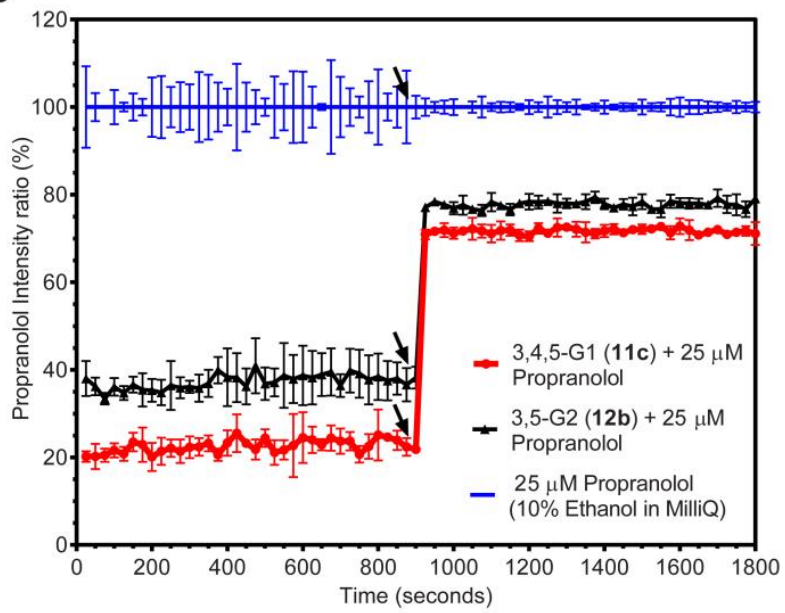

Fig. 6 a) Photograph of samples in the NR-loading experiment: Simple injection of I) Nile Red (NR), (II) Nile Red-ethanol mixture, (III) 3,4,5-G1 (11c), (IV) Nile Redloaded 3,4,5-G1 dendrimersomes in ethanol mixture, into Milli- $\mathrm{Q}^{\oplus}$. All Nile Red and Janus-dendrimer $3,4,5-\mathrm{G} 1$ concentrations were the same in the final volume b) fluorescence of Nile Red loaded 3,4,5-G1 (11c) and 3,5-G2 (12b) dendrimersomes and controls; and c) Propranolol loading into $11 \mathrm{c}$ and $12 \mathrm{~b}$ dendrimersomes (red and black, respectively) measured by relative fluorescence, i.e. the ratio of sample fluorescence and fluorescence control (blue, $25 \mu \mathrm{M}$ propranolol in $10 \%$ ethanol). The arrows denote the time when $50 \mu \mathrm{L} 3 \%$ Triton $\mathrm{X}-100$ solution was added in order to disrupt the samples and the control. Error bars represent \pm SD $(n=3)$.
Therefore, the confinement of PR in the dendrimersomes lead to higher local concentrations of $P R$ in 11c dendrimersomes than in $\mathbf{1 2 b}$ dendrimersomes which explains the lower relative fluorescence values measured for $\mathbf{1 1 c}$ compared to $\mathbf{1 2 b}$ before dendrimersome disruption. The addition of $50 \mu \mathrm{L}$ of $3 \%$ Triton $\mathrm{X}-100$ solution per $200 \mu \mathrm{L}$ of sample volume did not noticeably change the fluorescence intensity of the controls (data not shown), whereas the relative fluorescence values of the samples increased from $22.5 \pm 1.5 \%$ to $71.7 \pm 0.6 \%$ for $3,4,5-G 1$ (11c), and from $37.3 \pm 1.6 \%$ to $77.8 \pm 0.8 \%$ for $3,5-G 2$ (12b), confirming the presence of the quenched PR in the samples (Fig. $6 c)$. The increase in the fluorescence shows that intact dendrimersomes are required for efficient self-quenching of propranolol fluorescence. We assume that the relative fluorescence in disrupted 3,4,5-G1 (11c) dendrimersome samples was lower than in disrupted 3,5-G2 (12b) dendrimersome samples due to the slight difference in the molar dendrimer-to-drug ratios. The fluorescence intensities of the samples did not reach the intensity of the control samples even after all the samples and controls were treated with the Triton X-100 solution. This indicates that stronger associations took place between the dendrimers and PR than between Triton $\mathrm{X}-100$ and $\mathrm{PR}$, and that the disruption of the dendrimersome bilayers was incomplete since the self-quenching local concentrations of PR were maintained partially even after addition of the detergent. Slightly more negative $\zeta$-potentials were recorded for PR-loaded dendrimersomes compared with empty controls 3,4,5-G1 (11c: $-12.3 \pm 0.5 \mathrm{mV}$ vs. $-9.8 \pm 0.5 \mathrm{mV}$ ) and 3,5-G2 (12b: $-15.5 \pm 1.6 \mathrm{mV}$ vs. $-13.3 \pm 2.1 \mathrm{mV})$, and the Zaverage size of PR-loaded dendrimersomes 11c $(92.6 \pm 0.5 \mathrm{~nm}$, PDI 0.06) and $12 \mathbf{b}(132.1 \pm 2.1 \mathrm{~nm}, \mathrm{PDI} 0.03)$ was larger than the size of empty controls $11 \mathrm{c}(76.0 \pm 0.9 \mathrm{~nm}, \mathrm{PDI} 0.14)$ and $12 \mathrm{~b}$ $(86.4 \pm 0.9$, PDI 0.05), respectively. This is likely a charge-related phenomenon, since the addition of PR (a secondary amine) has been reported to expand monolayers with negatively charged polar head groups. ${ }^{61}$

\section{Conclusions}

In conclusion, we have shown the feasibility of copper(I)catalysed azide alkyne cycloaddition (CUAAC) reaction as an efficient and time-saving synthetic tool for preparing two generations of amphiphilic Janus-dendrimers having a 3,4-, 3,5and 3,4,5-branched skeleton. The straightforward fabrication, using a fast injection of dilute ethanol, THF, or acetone solution of Janus dendrimer into water, produced unilamellar and multilamellar dendrimersomes with extremely narrow size distribution, even when annealed at $70{ }^{\circ} \mathrm{C}$.

The injection of a mixture of Janus-dendrimer and the smallmolecule drug propranolol in dilute ethanol solutions into water resulted in simultaneous self-assembly and encapsulation of the model drug within dendrimersomes with high loading efficiency, measured by the ratio of intensity caused by the selfquenching of the drug. The robust shelf-life $(>4 \mathrm{mo})$ of the assemblies constructed from a 3,5- or 3,4,5-branched Janusdendrimers is remarkable and shows promise for development of uniform and injectable colloidal vesicles with sufficient 
stability for most drug delivery applications. The size of dendrimersomes in solution can be tuned by adjusting the final concentration, the branching sequence or the organic solvent from which Janus-dendrimers are injected.

The present toolbox for size modulation, accompanied with a fast and straightforward drug loading procedure via single-step injection in a reproducible fashion provides access to nanostructures in the $100 \mathrm{~nm}$ size range with narrow size distribution and high loading efficiency, suitable for intravenous administration. Thus, the results presented here open up new avenues for colloidal drug delivery systems and facilitate the development of application-specific, dual- or even multi-loaded dendrimersome-based delivery vehicles for drugs and other therapeutics, with further biomedical applications currently being investigated.

\section{Experimental Section}

\section{Materials}

All reagents and solvents were obtained from commercial sources (Fluka, Acros Organics, Merck, TCl Europe, Fisher, Rathburn and Sigma-Aldrich) and used without prior purification unless otherwise stated. Deuterated solvents for NMR analysis were purchased from Euriso-top (Saint Aubin Cedex, France). Dry dichloromethane and tetrahydrofuran were obtained from a solvent drier (MB-SPS-800, neutral alumina; MBraun, Germany) and used when necessary. Milli- $Q^{\circledR}$ purified water was used in all reactions and measurements (Millipore Synergy UV unit; $18.2 \mathrm{M} \Omega . \mathrm{cm}$ ).

\section{Preparation of dendrimersomes}

First, $10 \mathrm{mg} \mathrm{mL}^{-1}$ stock solutions in absolute $\mathrm{EtOH}$ and $5 \mathrm{mg} \mathrm{mL}$ ${ }^{1}$ stock solutions in THF and acetone of each Janus-dendrimer were prepared, respectively. Then, $100 \mu \mathrm{L}$ of the stock solution was injected quickly into $1.9 \mathrm{~mL}$ of Milli- $\mathrm{Q}^{\circledR}$ followed by $5 \mathrm{sec}$. of vortex mixing to obtain a final concentration of $0.5 \mathrm{mg} \mathrm{mL}^{-1}(0.9$ $\mathrm{mL}$ of Milli- $\mathrm{Q}^{\circledR}$ for THF or acetone). Different final concentrations of dendrimersomes, ranging from $0.1-4.0 \mathrm{mg}$ $\mathrm{mL}^{-1}$ (ethanol injection) and $0.1-1.0 \mathrm{mg} \mathrm{mL}^{-1}$ (THF and acetone injection) into Milli- ${ }^{\circledR}$ were obtained. No purification or further manipulation was applied. The stability studies using Foetal Bovine Serum (FBS) were conducted as follows: $10 \mu \mathrm{L}$ of dendrimer stock solution in ethanol $\left(c=30 \mathrm{mg} \mathrm{mL}^{-1}\right)$ was injected into $90 \mu \mathrm{L}$ Milli- ${ }^{\circledR}$ in plastic cuvettes. The resulting dendrimersomes were then diluted to a final concentration of $300 \mu \mathrm{g} \mathrm{mL}^{-1}$ by addition of $900 \mu \mathrm{L}$ of FBS. For each dendrimer, a control sample was prepared accordingly. The samples were capped and stored at $37^{\circ} \mathrm{C}$ for seven days. All the samples and controls were measured daily in triplicate by DLS. The Z-average size and changes in PDI were calculated from the analysis results and plotted using GraphPad Prism v. 6.07 (GraphPad Software, Inc., USA).

\section{Nuclear Magnetic Resonance (NMR) spectra}

${ }^{1} \mathrm{H}$ NMR (500 MHz) spectra and proton-decoupled ${ }^{13} \mathrm{C}$ NMR (125 $\mathrm{MHz}$ ) spectra were recorded on a $500 \mathrm{MHz}$ Bruker UltraShield
Plus spectrometer at $25^{\circ} \mathrm{C}$. Additional measurements were recorded on a Bruker Avance DPX400 spectrometer equipped with a $5 \mathrm{~mm}$ BBFO probehead. Hydrogen multiplicity $\left(\mathrm{CH}, \mathrm{CH}_{2}\right.$, $\mathrm{CH}_{3}$ ) was obtained from DEPT 135 experiments. Heteronuclear ${ }^{1} \mathrm{H}-{ }^{13} \mathrm{C}$ connectivity was determined by using HSQC experiments.

\section{Dynamic light scattering (DLS)}

Experiments were performed at least in triplicate at $25^{\circ} \mathrm{C}$ using a Zetasizer ${ }^{\circledR}$ Nano ZS (Malvern Instruments, UK) equipped with $4 \mathrm{~mW}$ He-Ne laser $633 \mathrm{~nm}$ and avalanche photodiode positioned at $173^{\circ}$ to the beam. For the temperature stability experiment samples were ramped in $5{ }^{\circ} \mathrm{C}$ intervals from $25^{\circ} \mathrm{C}$ to $70{ }^{\circ} \mathrm{C}$ with $30 \mathrm{sec}$. equilibration time in each temperature point. After cooling to $25{ }^{\circ} \mathrm{C}$, the samples were stabilized for 5 min. before measurement. For the zeta (द) potential, three independent measurements were conducted on samples injected from EtOH for a final concentration of $0.5 \mathrm{mg} \mathrm{mL}^{-1}$ of dendrimer in Milli- ${ }^{\circledR}$.

\section{Cryogenic-Transmission Electron Microscopy (cryo-TEM)}

Imaging was performed in a JEOL JEM-3200FSC liquid helium equipment (JEOL Ltd., Japan). Microscopy images were processed with public domain software ImageJ 1.48 (http://rsb.info.nih.gov/ij/).

\section{Confocal microscopy}

Images were obtained with a Leica TCS SP5 MP upright confocal microscope equipped with argon (488 $\mathrm{nm}$ ) and DPSS (561 nm) lasers, and using a HCX Plan Apochromat 20x/0.7 water immersion objective (Leica Microsystems, Germany). Z-stacks from the dendrimersomes were taken with $0.7 \mu \mathrm{m}$ thickness.

\section{UV spectroscopy}

The fluorescence of the propranolol free base samples was measured with an excitation wavelength of $296 \mathrm{~nm}$ and an emission wavelength of $332 \mathrm{~nm}$. A fluorescence scan of the Nile Red samples was conducted with an excitation wavelength of $552 \mathrm{~nm}$ and emission wavelengths between $580 \mathrm{~nm}$ and 700 $\mathrm{nm}$, with an excitation bandwidth of $5 \mathrm{~nm}$. The fluorescence of both compounds was measured in a Varioskan Flash fluorometer (Thermo Fisher Scientific Inc., USA).

\section{Acknowledgements}

Financial support by the Academy of Finland (decisions No. 138850 for S.N.; No. 276377 for L.M.B., No. 268616 for J.R. and No. 263504, 267497, and 273645 for M.A.K.), Sigrid Juselius Foundation, Instrumentarium Science Foundation, Magnus Ehrnrooth Foundation, Emil Aaltonen Foundation, Biocentrum Helsinki, The Finnish Cultural Foundation, Orion Research Foundation and Jane and Aatos Erkko Foundation is gratefully acknowledged. This work was carried out under the Academy of Finland's Centers of Excellence Programme (2014-2019) and made use of facilities and technical support by Aalto University at OtaNano - Nanomicroscopy Center (Aalto-NMC). Mr. H. 
Revitzer is thanked for Atomic Absorption Spectrometry (AAS) measurements.

\section{Notes and references}

J. Shi, A. R. Votruba, O. C. Farokhzad and R. Langer, Nano Lett., 2010, 10, 3223-3230.

M. Ferrari, Nat. Nanotechnol., 2008, 3, 131-132.

J. A. Champion and S. Mitragotri, Proc. Natl. Acad. Sci. U. S. A., 2006, 103, 4930-4934.

O. C. Farokhzad and R. Langer, ACS Nano, 2009, 3, 16-20.

M. E. Fox, F. C. Szoka and J. M. J. Fréchet, Acc. Chem. Res., 2009, 42, 11411151.

L. M. Bimbo, L. Peltonen, J. Hirvonen and H. A. Santos, Curr. Drug Metab. 2012, 13, 1068-1086.

V. P. Torchilin, Nat. Rev. Drug Discov., 2014, 13, 813-827.

C. LoPresti, H. Lomas, M. Massignani, T. Smart and G. Battaglia, J. Mater. Chem., 2009, 19, 3576-3590.

D. E. Discher and F. Ahmed, Annu. Rev. Biomed. Eng., 2006, 8, 323-341.

O. Onaca, R. Enea, D. W. Hughes and W. Meier, Macromol. Biosci., 2009, 9, 129-139.

E. K.-H. Chow and D. Ho, Sci. Transl. Med., 2013, 5, 1-12.

D. A. Tomalia, Prog. Polym. Sci., 2005, 30, 294-324.

D. A. Tomalia, Soft Matter, 2010, 6, 456-474.

S. M. Grayson and J. M. J. Fréchet, Chem. Rev., 2001, 101, 3819-3867.

D. A. Tomalia, J. B. Christensen, U. Boas, Dendrimers, dendrons and dendritic polymers, Cambridge University Press, New York, 2012.

A. W. Bosman, H. M. Janssen and E. W. Meijer, Chem. Rev., 1999, 99, 16651688.

S. Nummelin, M. Skrifvars and K. Rissanen, Top. Curr. Chem., 2000, 210, 167.

L. Röglin, E. H. M. Lempens and E. W. Meijer, Angew. Chem. Int. Ed., 2011, 50, 102-112.

C. Roche, H.-J. Sun, P. Leowanawat, F. Araoka, B. E. Partridge, M. Peterca, D. A. Wilson, M. E. Prendergast, P. A. Heiney, R. Graf, H. W. Spiess, X. Zeng, G. Ungar and V. Percec, Nat. Chem., 2016, 8, 80-89.

A. R. A. Palmans and E. W. Meijer, Angew. Chem. Int. Ed., 2007, 46, 89488968.

V. Percec, A. E. Dulcey, V. S. K. Balagurusamy, Y. Miura, J. Smidrkal, M.

Peterca, S. Nummelin, U. Edlund, S. D. Hudson, P. A. Heiney, H. Duan, S. N. Magonov and S. A. Vinogradov, Nature, 2004, 430, 764-768.

B. M. Rosen, C. J. Wilson, D. A. Wilson, M. Peterca, M. R. Imam and V. Percec, Chem. Rev., 2009, 109, 6275-6540.

J. Mikkilä, H. Rosilo, S. Nummelin, J. Seitsonen, J. Ruokolainen and M. A Kostiainen, ACS Macro Lett., 2013, 2, 720-724.

H.-J. Sun, S. Zhang and V. Percec, Chem. Soc. Rev., 2014, 44, 3900-3923. V. Percec, D. A. Wilson, P. Leowanawat, C. J. Wilson, A. D. Hughes, M. S. Kaucher, D. A. Hammer, D. H. Levine, A. J. Kim, F. S. Bates, K. P. Davis, T. P. Lodge, M. L. Klein, R. H. DeVane, E. Aqad, B. M. Rosen, A. O. Argintaru, M. J. Sienkowska, K. Rissanen, S. Nummelin and J. Ropponen, Science, 2010, 328 1009-1014.

A.-M. Caminade, R. Laurent, B. Delavaux-Nicot and J.-P. Majoral, New J. Chem., 2012, 36, 217-226.

E. Fedeli, A. Lancelot, J. L. Serrano, P. Calvo and T. Sierra, New J. Chem. 2015, 39, 1960-1967.

A. L. Acton, C. Fante, B. Flatley, S. Burattini, I. W. Hamley, Z. Wang, F. Greco and W. Hayes, Biomacromolecules, 2013, 14, 564-574.

I. Bury, B. Donnio, J.-L. Gallani and D. Guillon, Langmuir, 2007, 23, 619-625. V. Percec, M. R. Imam, T. K. Bera, V. S. K. Balagurusamy, M. Peterca and P. A. Heiney, Angew. Chem. Int. Ed., 2005, 44, 4739-4745.

J. Ropponen, S. Nummelin and K. Rissanen, Org. Lett., 2004, 6, 2495-2497. M. Peterca, V. Percec, P. Leowanawat and A. Bertin, J. Am. Chem. Soc., 2011, 133, 20507-20520.

S. Zhang, H.-J. Sun, A. D. Hughes, B. Draghici, J. Lejnieks, P. Leowanawat, A. Bertin, L. Otero De Leon, O. V. Kulikov, Y. Chen, D. J. Pochan, P. A. Heiney and V. Percec, ACS Nano, 2014, 8, 1554-1565.

S. Zhang, H.-J. Sun, A. D. Hughes, R.-O. Moussodia, A. Bertin, Y. Chen, D. J. Pochan, P. A. Heiney, M. L. Klein and V. Percec, Proc. Natl. Acad. Sci. U. S. A., 2014, 111, 9058-9063.

M. Filippi, V. Catanzaro, D. Patrucco, M. Botta, L. Tei and E. Terreno, J. Control. Release, 2017, 248, 45-52.

M. Filippi, D. Patrucco, J. Martinelli, M. Botta, P. Castro-Hartmann, L. Tei and E. Terreno, Nanoscale, 2015, 7, 12943-12954.

V. Percec, P. Leowanawat, H.-J. Sun, O. Kulikov, C. D. Nusbaum, T. M. Tran, A. Bertin, D. A. Wilson, M. Peterca, S. Zhang, N. P. Kamat, K. Vargo, D. Moock, E. D. Johnston, D. A. Hammer, D. J. Pochan, Y. Chen, Y. M. Chabre, T. C. Shiao, M. Bergeron-Brlek, S. André, R. Roy, H.-J. Gabius and P. A. Heiney, J. Am. Chem. Soc., 2013, 135, 9055-9077.

S. Zhang R-O. Moussodia, H.J. Sun, P. Leowanawat, A. Muncan, C. D. Nusbaum, K. M. Chelling, P. a. Heiney, M. L. Klein, S. André, R. Roy, H.-J. J. Gabius and V. Percec, Angew. Chem. Int. Ed., 2014, 53, 10899-10903.

S. Zhang, R.-O. Moussodia, S. Vértesy, S. André, M. L. Klein, H.-J. Gabius and V. Percec, Proc. Natl. Acad. Sci., 2015, 112, 5585-5590.

S. Zhang, R.-O. Moussodia, C. Murzeau, H.-J. Sun, M. L. Klein, S. Vértesy, S. André, R. Roy, H.-J. Gabius and V. Percec, Angew. Chem. Int. Ed., 2015, 54, 4036-4040.

Q. Xiao, S. Zhang, Z. Wang, S. E. Sherman, R.-O. Moussodia, M. Peterca, A. Muncan, D. R. Williams, D. A. Hammer, S. Vértesy, S. André, H.-J. Gabius, M. L. Klein and V. Percec, Proc. Natl. Acad. Sci. U. S. A., 2016, 113, 1162-1167. A. Nazemi and E. R. Gillies, Chem. Commun. (Camb)., 2014, 50, 1112211125

M. Filippi, J. Martinelli, G. Mulas, M. Ferraretto, E. Teirlinck, M. Botta, L. Tei and E. Terreno, Chem. Commun. (Camb)., 2014, 50, 3453-3456. G. Franc and A. K. Kakkar, Chem. Soc. Rev., 2010, 39, 1536-1544. H. Ihre, A. Hult and E. Söderlind, J. Am. Chem. Soc., 1996, 118, 6388-6395. M. Malkoch, E. Malmström and A. Hult, Macromolecules, 2002, 35, 83078314

N. Feliu, M. V. Walter, M. I. Montañez, A. Kunzmann, A. Hult, A. Nyström, M. Malkoch and B. Fadeel, Biomaterials, 2012, 33, 1970-1981. J. S. Moore and S. I. Stupp, Macromolecules, 1990, 23, 65-70. C. Gunawan, W. Y. Teoh, C. P. Marquis and R. Amal, ACS Nano, 2011, 5, 7214-7225.

M. E. Davis, Z. G. Chen and D. M. Shin, Nat. Rev. Drug Discov., 2008, 7, 771782.

A. Nagayasu, T. Shimooka and H. Kiwada, Biol. Pharm. Bull., 1995, 18, 10201023.

A. Nagayasu, K. Uchiyama and H. Kiwada, Adv. Drug Deliv. Rev., 1999, 40, 75-87.

E. P. Holowka, D. J. Pochan and T. J. Deming, J. Am. Chem. Soc., 2005, 127 12423-12428.

J. Voskuhl and B. J. Ravoo, Chem. Soc. Rev., 2009, 38, 495-505. A. Bigdeli, S. Palchetti, D. Pozzi, M. R. Hormozi-Nezhad, F. Baldelli Bombelli, G. Caracciolo and M. Mahmoudi, ACS Nano, 2016, 10, 3723-3737. M. Lundqvist, J. Stigler, G. Elia, I. Lynch, T. Cedervall and K. A. Dawson, Proc. Natl. Acad. Sci. U. S. A., 2008, 105, 14265-14270.

S. Nummelin, V. Liljeström, E. Saarikoski, J. Ropponen, A. Nykänen, V. Linko, J. Seppälä, J. Hirvonen, O. Ikkala, L. M. Bimbo and M. A. Kostiainen, Chem. Eur. J., 2015, 21, 14433-14439.

S. D. Fowler and P. Greenspan, J. Histochem. Cytochem., 1985, 33, 833-836. C. Barzanti, R. Evans, N. M. Howarth, G. Kean, E. Levet, D. Wang, E. Wayemberg, A. A. Yeboah and A. Kraft, Tetrahedron Lett., 2007, 48, 33373341.

W. Surewicz and W. Leyko, Biochim. Biophys. Acta, 1981, 643, 387-397. R. Bisby, S. Botchway, A. Crisostomo, J. Karolin, A. Parker and L. Schröder, Spectroscopy, 2010, 24, 137-142. 